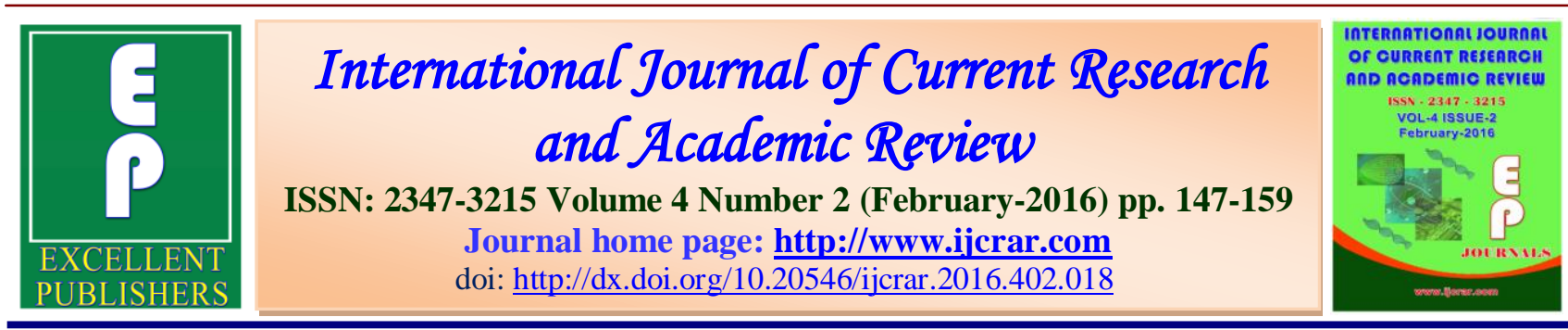

\title{
Over expressed miRNA-31 is the Most Consistent and Unique Micro RNA in Ulcerative Colitis
}

Yifei Cao ${ }^{1}$, Chengtan $\mathrm{Li}^{1}$, Wen $\mathrm{Li}^{2}$, Yani Chen ${ }^{1}$, WeibinCai ${ }^{1}$, XiaohuaTan ${ }^{1}$, Liangwen $\mathrm{Xu}^{1}$, Lei Yang ${ }^{1}$ and Yutao Yan ${ }^{*}$

${ }^{1} 16$ Xuelin St. School of Medicine, Hangzhou Normal University, Hangzhou 310036, Zhejiang, China

${ }^{2} 2$ Ravinia Drive, Suite 1750, IHRC inc. Atlanta, Georgia, 30346, USA

*Corresponding author

KEYWORDS

Ulcerative colitis, miRNA,

Systematic study, and

Differential

expression
A B S T R A C T

Recently, several micro RNA (miRNA) profiling studies have been performed on ulcerative colitis (UC) tissues but with extremely inconsistency, their diagnostic or therapeutic value remains debate. Thus, this study aims to systematically evaluate the consistency of miRNAs from multiple independent studies. Eligible studies were collected from online programs, followed by a systematic analysis on miRNAs. Real time PCRs were employed to validate miRNA candidates. The target genes of high consistent miRNAs were collected with online programs. Enrichment analyses for gene ontology (GO) terms and Kyoto encyclopedia of genes and genomes (KEGG) pathways were carried out. A total of 272differentially expressed miRNAs were reported in 10 profiling studies, of which 166 were upregulated and 106 were down regulated. In the group of consistently up-regulated miRNAs (cutoff $>4$ times), miRNA-31 was the only miRNA found in 5 different studies. Among the 106 down-regulated miRNAs, none of them expressed consistently in more than 4 different studies. The increased miRNA-31 was confirmed by real-time PCR. Enrichment analyses demonstrated that the regulation of transcription and metabolic process play important roles during the interplay of miRNAs with UC. Conclusion: This systematic study demonstrates that pro-inflammatory miRNA-31 is the only consistently differently expressed miRNA.

\section{Introduction}

Ulcerative colitis (US), one of the two main forms of inflammatory bowel diseases (IBD), is caused by inappropriate and continuing immunologic responses to aberrant intestinal microorganisms under certain environmental conditions in 
genetically susceptible individuals, characterized by compromised epithelium integrity and passive leaking bloody diarrhea (Abraham \& Cho, 2009). As an intermittent disease, UC demonstrates periodic symptom-free and periodic exacerbating symptoms, with the increasing incidence of 1 to 20 cases per 100,000 individuals per year and a prevalence of 8 to 246 per 100,000 individuals (Danese \& Fiocchi, 2011).No direct causes were known thus far, but many factors might contribute to the onset and progression of UC, such as genetic factors and environmental factors. Many studies, such as on ethnic differences in incidence of UC, aggregation of UC in families, and different concordance rate between identical twin (10\%) and dizygotic twin (3\%), all demonstrate that genetic susceptibility is involved in the pathogenesis of UC (Danese \& Fiocchi, 2011). lately, certain amounts of genomic regions were identified being linked to UC, which are corresponding to variety of functional molecules such as hepatocyte nuclear factor 4A (HNF4A) (Consortium et al., 2009), tumor necrosis factor (TNF) receptor super family members (TNFRSF14, TNFRSF9) (Anderson et al., 2011). Besides these genetic factors, some environmental factors also contribute to the development of UC, such as diet, breastfeeding, and smoking.

The increasing incidence and prevalence are in a great extent due to the limits of appropriate diagnosis and therapeutic options. As far as diagnosis is concerned, except the initial diagnostic and non-specific workup like stool culture and C-reactive protein, endoscopy still remains as the golden standard for UC, but with the risk of perforation of the inflamed and compromised colon mucosa. For the treatment of UC, classic 5-ASA and corticosteroids are first line drugs, but their risks are sometimes overweighs benefits; biologic drugs TNF inhibitors inflixi mab and adalimu mab are the drug of choice for UC patients who are not responding to corticosteroid but probably cause harsh side effects such as mild heart failure; tuberculosis and even other fatal infection, which halt them from being used in a large scale. As short, even very promising advances have been achieved to understand the pathogenesis of UC in recent years, utility of early and proper diagnosis and ideal therapeutic optionsare still quite challenging.

Since discovered in early 1990s, microRNAs (miRNAs)have been found enable to regulate the expression of up to $30 \%$ encoding genes by binding to specific mRNA targets, thus promoting their degradation and/or translational inhibition, or compromising the mRNA stability (Bartel, 2004, Fabian et al., 2010). Based on its involvement in a variety of essential cellular processes including development, cell differentiation, proliferation, and apoptosis, miRNAs are poised to make significant contributions to not only tumorigenesis, but also pathogenesis of inflammation by functioning as proinflammatory (Kurowska-Stolarska et al., 2011) or anti-inflammatory factors(Sun et al., 2013). Thus, miRNAs are implied potential as biomarkers and intervention targets against inflammatory disorders, including UC (Lin et al., 2013, Schaefer et al., 2015). Beyond these, an important feature of miRNA is their remarkable stability, for example, they can be well preserved in tissue samples even after formalin-fixation and paraffin embedding for years, and can be efficiently extracted from such specimens and variety of cell lines (Finkel et al., 2007). Actually, several endeavors have been imposed to search for biomarkers or therapeutic agents by identifying the differentially expressed miRNAs between UC inflamed tissue and 
corresponding non-inflamed tissue ( $\mathrm{Wu}$ et al., 2008, Fasseu et al., 2010, Takagi et al., 2010, Olaru et al., 2011, Olaru et al., 2013, Coskun et al., 2013, Van der Goten et al., 2014, Lin et al., 2014, Schaefer et al., 2015, Hubenthal et al., 2015). These studies generated hundreds of differentially expressed miRNAs, however, many of these are likely limited by different bias and finally only a small number of them may be of clinical significance and act as potential diagnostic agents. Further, different profiling studies showed quite inconsistency in the identified differentially expressed miRNAs. Third, in miRNA-based therapeutics, miRNAs are tissue specific and their role depends on cellular context. For instance, miR146afunctions as an antiinflammatory factor in epithelium and airway smooth muscle (Comer et al., 2014) and a pro-inflammatory factor in brain (Taganov et al., 2006) (Comer et al., 2014). It is therefore crucial to select intestinal tissue specific and consistently differentially expressed miRNAs and to investigate their potential as biomarkers or therapeutic agents.

We conducted this systematic analysis to screen the most consistently and differentially expressed miRNAs from a series of independent miRNA profiling studies in UC patients. Further, we confirmed these most up- or down regulated miRNAs by quantitative PCR in 15 pairs of $\mathrm{UC}$ and their paired non-inflamed tissue sample.

\section{Materials and Methods}

\section{Literature Strategy}

In order to find as many as literatures, candidate profiling studies of miRNAs published in English were collected from Pubmed and EMBASE published from April 2008 to October 2015 (last accessed on
December 15,2015$)$ by two investigators using the following medical subject headings terms: 'ulcerative colitis' and "microRNAs' or "miRNA" in combination with the key words 'profiling' or "RNA sequencing" or "microarray".

\section{Study Selection Criteria}

The inclusion criteria of literatures in this systematic analysis were based on miRNA profiling studies (mainly miRNA microarray and sequencing) published previously in UC inflamed tissues and their adjacent noninflamed tissues for comparison, and only full-text publications in English were included. Therefore, miRNA profiling studies that used serum samples of UC patients or intestinal relevant cell lines or those using different miRNA techniques were excluded. Review articles were also excluded.

\section{Data Collection}

Two investigators (Y.C. and C.L.) independently evaluated and extracted the data using standard protocols, and all discrepancies were resolved by corresponding investigator (Y.Y.). From the full text and corresponding supplementary information, the following eligibility items were collected and recorded for each study: author, journal and year of publication, location of study, platform of miRNA expression profiling, author defined cut-off criteria of statistically significant differentially expressed miRNAs.

\section{Ranking}

Each of the published miRNA expression profiling studies comparing miRNA expression between inflamed and noninflamed control intestinal tissues provided a list of differentially expressed miRNAs (Wu et al., 2008, Fasseu et al., 2010, Takagi et 
al., 2010, Olaru et al., 2011, Olaru et al., 2013, Coskun et al., 2013, Van der Goten et al., 2014, Lin et al., 2014, Schaefer et al., 2015, Hubenthal et al., 2015). For example, Hubenthal et al (Hubenthal et al., 2015) carried out comprehensive analysis of UCrelated miRNAs based on a large number of miRNA profiling studies.

The potential biomarkers for comparison groups were ranked by a method described previously, which has been used for profiling like meta-analysis studies (Griffith et al., 2006). Briefly, miRNAs were ranked to the criteria in the order of importance, such as the consistency, difference and frequency of target miRNAs in included studies and their total sample size.

\section{Validation of the Selected miRNA-31}

To confirm the profiling results, 15 fresh UC tissues and their paired non-inflamed tissues were obtained from the Second Hospital of Hangzhou City, affiliated to Hangzhou Normal University School of Medicine. The diagnosis of UC was based on clinical and histological criteria. Clinical data for UC patients were obtained by medical record review. The collection of samples from patients were approved by the Institutional Review Board of Hangzhou Normal University and performed after written informed consent was obtained. Total RNA was extracted using TRIzol reagent (Life technology, Casbad, Ca, USA) according to the manufacturer's instructions.

The differentially expressed amount of the miRNAs was validated in triplicate by real time PCR. Briefly, Reverse transcription from $3 \mu \mathrm{g}$ RNA was done using SuperScript III First-Strand Synthesis System (Life technology, Casbad, Ca, USA) according to the manufacturer's protocol. Real-time PCR was performed using iQ SYBR Green
Supermix kit (Bio-Rad, Hercules, CA) with the iCycler sequence detection system (BioRad) with miRNA-31specific primers (For: GGAGAGGAGGCAAGATGCTGG Rev: GGAAAGATGGCAATATGTTGG). Small nucleolus RNA U6 (For: GCGCG TCGTGAAGCGTTCRev:GTGCAGGGTC CGAGGT) was used as an internal standard for normalization. The cycle threshold $\left(\mathrm{C}_{\mathrm{T}}\right)$ value was calculated. The $2^{-\Delta \mathrm{CT}}$ $\left(\Delta \mathrm{C}_{\mathrm{T}}=\mathrm{C}_{\mathrm{TmiR}}-\mathrm{C}_{\mathrm{TU6}} \mathrm{RNA}\right)$ method was used to quantify the relative amount of miRNAs.

\section{Identify the Experimentally Validated MicroRNA Target Genes}

To explore the target genes of miRNAs related to UC miRTar Base (mirtarbase.mbc.nctu.edu.tw), micro RNA.org and Target Scan Human 6.2 were used to explore all the target genes of miRNAs, and highlighted the genes that are experimentally validated by luciferase reporter assay, western blot, or microarray experiments with over expression or knockdown of miRNAs.

\section{Enrichment Analysis}

Enrichment analyses for gene ontology (GO) terms and Kyoto encyclopedia of genes and genomes (KEGG) pathways were carried out with Database for Annotation, Visualization, and Integrated Discovery (DAVID)(Dennis et al., 2003). For this, we listed all the target genes of miRNA-31. The top 10 terms and KEGG pathways showing association with target genes were listed with GO terms, KEGG pathway, number of genes in the GO term, number of genes in the KEGG pathways.

\section{Statistical Analysis}

Student's t-test was used to compare values between two independent groups. 


\section{Results and Discussion}

A total of 81 studies were recorded using PubMed and EMBASE. 56 of which were excluded after screening the titles and abstracts and 15 studies were excluded after reading the full text based on the inclusion and exclusion criteria, only 10 independent studies were included in this systematic analysis. The detailed workflow used in our analysis was shown in Figure 1, which is adapted and modified from PRISMA guidance (Stewart et al., 2015). The detailed characteristics of each study are given in Table 1 in the descending order of their year of publication.

\section{Differentially Expressed miRNAs}

These 10 studies from 10 different groups with different platforms, different number of samples, and various statistical analyses had been employed for miRNA profiling analysis to compare UC tissue with corresponding non-inflamed colon tissue. The number of differentially expressed microRNAs ranges from 7 to 59. A total of 272 differentially expressed miRNAs were reported in the 10 profiling studies. 106miRNAs are down regulated in UC, and 166 microRNAs are up regulated. Among the 106 down-regulated miRNAs, no miRNAs were consistently decreased more than 4 times (cut off $>4$ ).Among the 166 upregulated miRNAs, there is onlymiRNA-31 found increased in 5different studies (Olaru et al., 2011, Olaru et al., 2013, Coskun et al., 2013, Van der Goten et al., 2014, Lin et al., 2014), the total number of tissue samples were the addition of these five individual studies is 404, including 266 UC patients and 138 healthy volunteers. We also noticed that these selected miRNAs differentially expressed in a very inconsistent manner in these 10 profiling studies. For example, in the groups of inconsistently reported miRNAs, miRNA-199a was reported down- regulated in two studies but up-regulated in another two separate studies; miRNA-16 was increased in 3 studies but downregulated in 1 studies (Table 3), respectively.

\section{Validation of the Selected miRNA}

To validate the increased expression of miRNA-31, real-time PCR with specific primers were performed with samples from15 pair UC biopsies and adjacent noninflamed tissues. The results showed that miRNA-31 were up-regulated significantly in UC patients (Figure 2), which were consistent with those original corresponding profiling studies.

\section{Target Genes of miRNA-31}

After we identified the most consistently upregulated miRNA-31in UC, we screened their potential target genes with programs such as miRTarBase (mirtarbase. mbc.nctu.edu.tw), microRNA.org and TargetScanHuman 6.2, focusing on the genes which were confirmed either by real time PCR, western blot, microarray or luciferase assay. As a result, we identified 51 target genes corresponding to the upregulated miRNA-31 in UC (data not shown).

\section{Enrichment Analysis Result}

We used DAVID program to build up the molecular networks corresponding to the target genes of miRNA-31. The top $10 \mathrm{GO}$ terms with more than 7 target genes involved, as demonstrated by Figure 3, show significant association with target genes were listed, These significant GO terms are related to the regulation of transcription and metabolic process. Since only miRNA-31 was selected by our systematic analysis, and the studies about miRNA-31 are still in the initial phase, there are no KEGG pathway 
built up yet, which further encourage us to pursue the function of miRNA-31 in pathogenesis of UC.

In the current study, we established the concept, by conducting a systematic analysis, which miRNA-31, the only consistently and differentially expressed miRNAs in UC, may be of significance for pathogenesis of UC. The potential targets of these selected miRNAs conduct the signaling pathways critical for regulation of transcription and metabolic process. Together, even almost all the other miRNAs identified inthis research may only play marginal roles in pathogenesis of UC, miRNA-31 harbors dramatic potential as a biomarker and therapeutic target for UC.

The usage of many classic UC biomarkers (such as anti-neutrophil cytoplasmic antibodies (cANCA, sANCA, pANCA); Creactive protein (CRP), Ferritin, Trasferrin, etc)is limited for their poor either sensitivity or specificity, for example, only $20 \%-85 \%$ of patients with UC have presence of ANCAs, similar situation seen in CRP with high sensitivity (72-96\%) but low specificity (34-64\%)(Mosli et al., 2015). Therapeutic drugs for UC either show risk overweighing benefits(like 5-ASA), or with mild heart failure (like infliximab). Thus, there is a critical need to obtain reliable biomarkers that allow diagnosis with ideal sensitivity and specificity, and precisely monitoring the pathogenic process and therapeutic alternatives of UC. Many miRNAs are deregulated significantly even in early stages of many acute inflammatory conditions, exhibiting their diagnostic and therapeutic potential. However, miRNA profiling studies were performed on different platforms and very different processing methods by different investigators, their lacks the common concert among these studies, consequently, which may end with inconsistent miRNAs expression profile(Wu et al., 2008, Fasseu et al., 2010, Takagi et al., 2010, Olaru et al., 2011, Olaru et al., 2013, Coskun et al., 2013, Van der Goten et al., 2014, Lin et al., 2014, Schaefer et al., 2015, Hubenthal et al., 2015). Surprisingly, by systematic analysis, we found that only miRNA-31 is sorted out among all the miRNAs over expressed in UC patients, none of others are either highly consistently expressed (cut off $>4$ ), further, among the down-regulated miRNAs in UC, none of them are consistently expressed (cut off $>4$ ). The reasons why miRNA-31was the only one selected in our systematic analysis are complicated, except the fact that both environmental factors are important in the pathogenesis of UC, miRNA-31 plays crucial roles in intestinal development and homeostasis, particularly, miRNA-31 can function as both oncogene and tumor suppressor, and pro-inflammatory and antiinflammatory factor.

MiRNAs can act as anti-inflammatory or pro-inflammatory genes in the onset and development of inflammation. By systematic analysis, we found that only miRNA-31 is enhanced, displaying proinflammatory characteristics, the underlying mechanisms may be complicated, for example, miRNA-31 was demonstrated to negatively regulate FOXP3, the master regulator in T-lymphocyte development and function, which is through direct binding of miRNA-31 at its target site in the 3'UTR of FOXP3 gene(Rouas et al., 2009).miRNA31can also down-regulate the expression of E-selectin, E-selectin is upregulated by some proinflammatory cytokines such as TNFalphaand plays an important part in recruiting leukocytes to the site of injury during inflammation (Pooley et al., 1995, Suarez et al., 2010); miRNA-31 is believed to contribute to angiogenesis as an angiomir (Caporali \& Emanueli, 2011), Angiogenesis- 
Int.J.Curr.Res.Aca.Rev.2016; 4(2): 147-159

related VEGF can increase the expression of miRNA-31 and promote intestinal angiogenesis and inflammation (Scaldaferri et al., 2009).In addition to UC, miRNA-31 is over expressed in psoriasis and Modulates
Inflammatory Cytokine and Chemokine Production in Keratinocytes via Targeting Serine/Threonine Kinase $40(\mathrm{Xu}$ et al., 2013).

Table.1 Characteristics of Mirna Datasets in Hepatocellular Carcinoma

\begin{tabular}{|c|c|c|c|c|c|c|c|c|}
\hline Author & Year & Region & Platform & $\begin{array}{c}\text { Number of } \\
\text { tissues }\end{array}$ & $\begin{array}{c}\text { Differently } \\
\text { expressed } \\
\text { miRNAs }\end{array}$ & Criteria & $\begin{array}{l}\text { Up- } \\
\text { regulated } \\
\text { miRNAs in } \\
\text { UC }\end{array}$ & $\begin{array}{l}\text { Down- } \\
\text { regulated } \\
\text { miRNAs } \\
\text { in UC }\end{array}$ \\
\hline $\begin{array}{l}\text { FENG } \\
\text { WU }\end{array}$ & 2008 & Maryland & $\begin{array}{c}\text { GenePix 4000B scanner (Molecular Devices, } \\
\text { Downing-town, PA) }\end{array}$ & $45(30 / 15)$ & 18 & $\mathrm{P}<0.05$ & 12 & 6 \\
\hline $\begin{array}{l}\text { Tomohisa } \\
\text { Takagi }\end{array}$ & 2009 & Japan & $\begin{array}{l}\text { the NCode rapid miRNA labeling system } \\
\text { (Invitrogen Japan, Tokyo, Japan) }\end{array}$ & $156(96 / 60)$ & 7 & $\mathrm{P}<0.01$ & 7 & \\
\hline $\begin{array}{l}\text { Mehmet } \\
\text { Coskun }\end{array}$ & 2013 & Denmark & $\begin{array}{l}\text { Geniom Real Time Analyzer(GRTA) (Febit } \\
\text { GmbH, Heidelberg, Germany) }\end{array}$ & $39(19 / 20)$ & 47 & $\mathrm{P}<0.05)$ & 47 & \\
\hline $\begin{array}{c}\text { Jan Van } \\
\text { der Goten }\end{array}$ & 2014 & Belgium & $\begin{array}{l}\text { Affymetrix GeneChip miRNA } 2.0 \text { arrays } \\
\text { (Affymetrix, Santa Clara,CA, USA) }\end{array}$ & $27(17 / 10)$ & 49 & $\begin{array}{l}\mathrm{FDR}<0.05 \\
\mathrm{LogFC}>2\end{array}$ & 24 & 25 \\
\hline $\begin{array}{l}\text { Jingmei } \\
\text { Lin }\end{array}$ & 2014 & USA & $\begin{array}{l}\text { the TaqMans miRNA Reverse Transcription } \\
\text { Kit(Applied Biosystems } \\
\text { by Life Technologies, Grand Island, NY, USA) }\end{array}$ & $65(36 / 29)$ & 9 & $\mathrm{P}<0.05$ & 5 & 4 \\
\hline $\begin{array}{l}\text { Magali } \\
\text { Fasseu }\end{array}$ & 2010 & France & 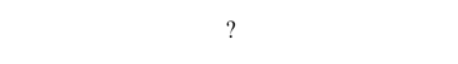 & $16(8 / 8)$ & 28 & $\mathrm{p} \leqslant 0.05$ & 16 & 12 \\
\hline $\begin{array}{l}\text { Alexandru } \\
\text { V. Olaru }\end{array}$ & 2011 & USA & $\begin{array}{l}\text { miR Labeling Reagent and Hybridization } \\
\text { Kits (Agilent Technologies, PaloAlto, CA) }\end{array}$ & $134(98 / 36)$ & 28 & $\mathrm{p}<0.001$ & 19 & 9 \\
\hline $\begin{array}{l}\text { Alexandru } \\
\text { V. Olaru }\end{array}$ & 2014 & USA & $\begin{array}{l}\text { MiR Labeling Reagent and Hybridization Kits } \\
\text { (Agilent Technologies, Palo Alto, CA, USA) }\end{array}$ & $162(107 / 55)$ & 28 & $\mathrm{P}<0.05$ & 16 & 12 \\
\hline $\begin{array}{l}\text { Jeremy S } \\
\text { Schaefer }\end{array}$ & 2015 & $?$ & The PAXgene Blood miRNA Kit (PreAnalytiX) & $76(41 / 35)$ & 42 & $\mathrm{P}<0.05$ & 10 & 32 \\
\hline $\begin{array}{l}\text { Matthias } \\
\text { Hübenthal }\end{array}$ & 2015 & Germany & $\begin{array}{l}\text { the miRNeasy Mini Kit (Qiagen GmbH, } \\
\text { Hilden, Germany) }\end{array}$ & $74(38 / 36)$ & 16 & $\mathrm{P}<0.05$ & 10 & 6 \\
\hline
\end{tabular}

Table.2 Inconsistency of Differentially Expressed Mirnas

\begin{tabular}{cccccc}
\hline miRNA & $\begin{array}{c}\text { N\# of in up-regulated } \\
\text { miRNA }\end{array}$ & $\begin{array}{c}\text { N\# of in down- } \\
\text { regulated miRNA }\end{array}$ & miRNA & $\begin{array}{c}\text { N\# of in up- } \\
\text { regulated miRNA }\end{array}$ & $\begin{array}{c}\text { N\# of in down- } \\
\text { regulated miRNA }\end{array}$ \\
\hline 16 & 3 & 1 & 424 & 3 & 1 \\
24 & 3 & 1 & 429 & 1 & 1 \\
141 & 1 & 2 & 1201 & 1 & 1 \\
150 & 1 & 1 & $146 \mathrm{~b}$ & 1 & 1 \\
155 & 3 & 1 & $196 \mathrm{a}$ & 1 & 2 \\
192 & 1 & 3 & $199 \mathrm{a}$ & 2 & 2 \\
194 & 1 & 2 & $199 \mathrm{~b}$ & 1 & 1 \\
192 & 2 & 1 & $200 \mathrm{a}$ & 2 & 1 \\
214 & 1 & 1 & $200 \mathrm{~b}$ & 2 & 2 \\
215 & 1 & 3 & $200 \mathrm{c}$ & 1 & 1 \\
223 & 3 & 1 & $20 \mathrm{a}$ & 1 & 1 \\
335 & 1 & 2 & $99 \mathrm{~b}$ & 2 & 2 \\
375 & 1 & & & $29 \mathrm{~b}$ & 1 \\
\hline
\end{tabular}


Int.J.Curr.Res.Aca.Rev.2016; 4(2): 147-159

Figure.1 Flowchart for this Systematic Analysis

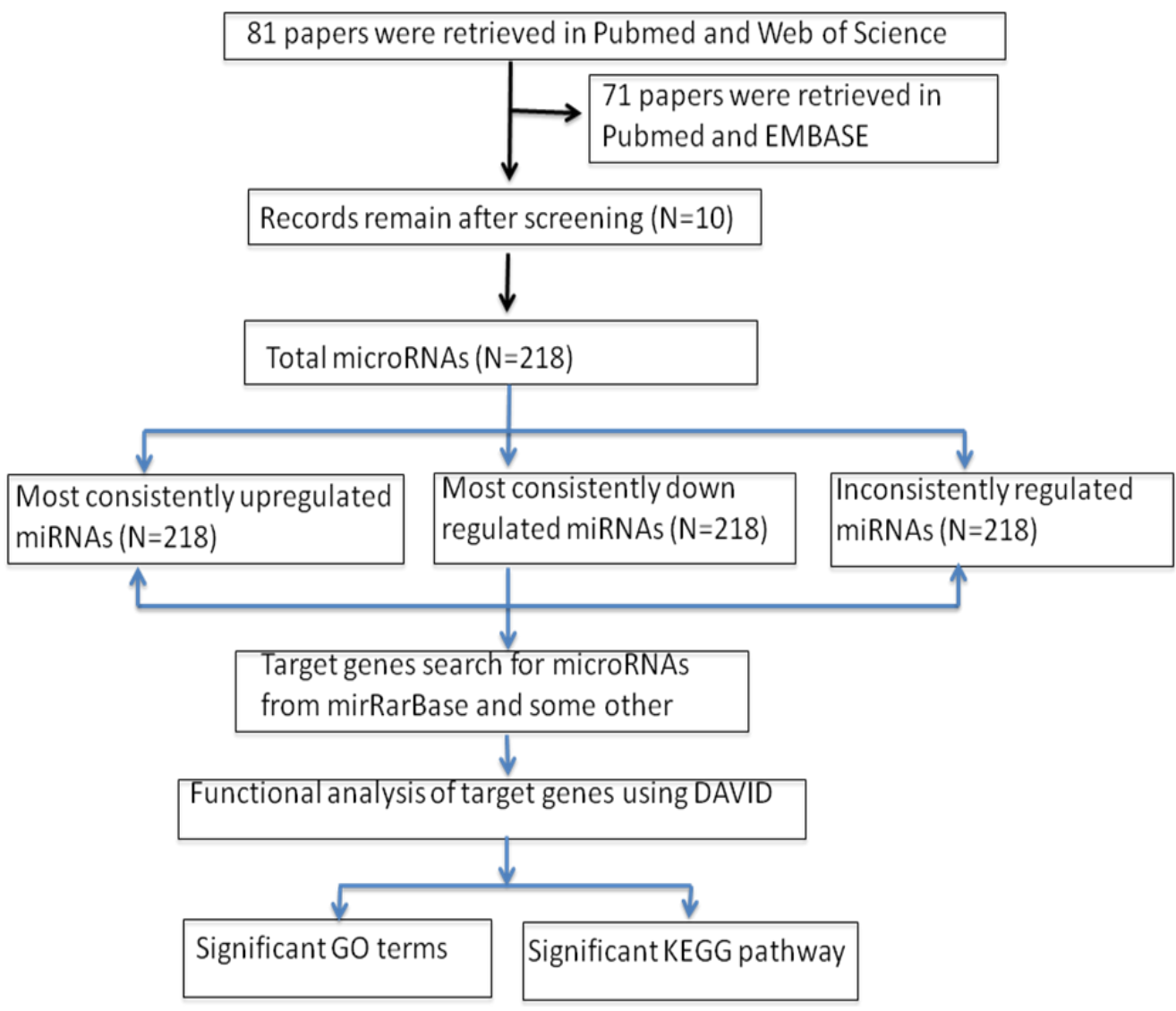

Figure.2 Real-time pcr analysis of the most consistently differentially expressedmirna31 expression of mir-31 is dramatically decreased in ucin comparison with adjacent non-inflamed tissue analyzed by real time pcr, $\mathrm{u} 6$ here functions as an internal control, and values represent means \pm s.e. Of three determinations. ${ }^{* *}, \mathrm{p}<0.01$

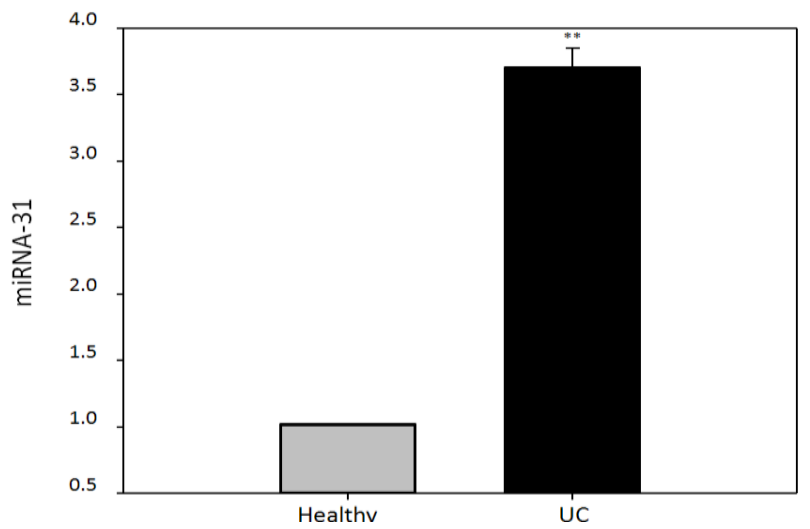


Figure.3 GO Analysis of Target Genes from most down-regulated miRNAs in selected profiling studies. Predicted target genes are mainly involved in inflammation related cellular process such asregulation of transcription and metabolic process. The top $10 \mathrm{GO}$ terms with more than 7 target genes involved show significant association with target genes and are related to the regulation of transcription and metabolic process

\begin{tabular}{|c|c|c|c|}
\hline 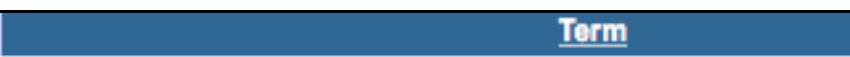 & 사 $\mathrm{RT}$ & Genes & Count \\
\hline transcription & $\underline{\mathbf{R T}}$ & - & 18 \\
\hline regulation of transcription & $\underline{\mathbf{R T}}$ & $\bar{E}$ & 18 \\
\hline modification-dependent macromolecule catabolic process & $\underline{\mathbf{R T}}$ & $\overline{\mathbf{a}}$ & 7 \\
\hline modification-dependent protein catabolic process & $\underline{\mathbf{R T}}$ & $\overline{\mathbf{a}}$ & 7 \\
\hline proteolysis involved in cellular protein catabolic process & $\underline{\mathbf{R T}}$ & E & 7 \\
\hline cellular protein catabolic process & $\underline{\mathbf{R T}}$ & $\overline{\mathbf{a}}$ & 7 \\
\hline protein catabolic process & $\underline{\mathbf{R T}}$ & - & 7 \\
\hline regulation of RNA metabolic process & $\underline{\mathbf{R T}}$ & $\overline{\mathbf{a}}$ & 12 \\
\hline cellular macromolecule catabolic process & $\underline{\mathbf{R T}}$ & $\bar{a}$ & 7 \\
\hline macromolecule catabolic process & $\underline{\text { RT }}$ & E & 7 \\
\hline
\end{tabular}

miRNAs function as proinflammatory or anti inflammatory factors by involving multiple molecular mechanisms. By enrichment analysis, we found that miRNA31 can targets variety of substrate genes, it is of great significance to point out that these target genes are involved in the inflammation-related cellular process, including regulation of transcription and metabolic process, which is in concert with the fact that transcription and metabolic process play critical roles in metabolism and inflammation (Medzhitov \& Horng, 2009, Kersten, 2010), which further highlight the importance of these miRNAs as potential biomarkers or therapeutic alternatives. Since our research only sorted out one microRNAmiRNA-31, and the studies on miRNA-31 are still very preliminary, KEGG pathways analysis by DAVID did not come up with very meaningful networks, which further encourage us to pursue the roles of miRNA31 in the pathogenesis of UC.

\section{Limitations}

Several limitations of this research should be considered when interpreting the results due to some unsolvable reasons. Firstly, our literature searching was depended on English databases only, as a result, language bias may present. Secondly, our study did not include all the populations (only Chinese, Korean, American, German, and Greece), so the result may not be able to apply to other populations such as Latin American, Japanese and African.

\section{Conclusion}

We performed comprehensive literature search in multiple databases by limiting publication language, date and key words. Based on systematic analysis, only the most consistently expressed miRNA-31 was filtered with up-regulated expression in 5 individual studies, but no down-regulated 
miRNAs with high consistency were found. By DAVID analysis, we showed that the target genes are mainly involved in the regulation of transcription and metabolic process.

\section{Acknowledgement}

This work was supported by grants from the Natural Science Foundation of China (81570479), the Climbing Program in Hangzhou Normal University-Phase (PF14002004021).

\section{References}

Abraham, C. and J. H. Cho, 2009: Inflammatory bowel disease. $N$ Engl $J$ Med,361, 2066-2078.

Anderson, C. A., G. Boucher, C. W. Lees, A. Franke, M. D'Amato, K. D. Taylor, J. C. Lee, P. Goyette, M. Imielinski, A. Latiano, C. Lagace, R. Scott, L. Amininejad, S. Bumpstead, L. Baidoo, R. N. Baldassano, M. Barclay, T. M. Bayless, S. Brand, C. Buning, J. F. Colombel, L. A. Denson, M. De Vos, M. Dubinsky, C. Edwards, D. Ellinghaus, R. S. Fehrmann, J. A. Floyd, T. Florin, D. Franchimont, L. Franke, M. Georges, J. Glas, N. L. Glazer, S. L. Guthery, T. Haritunians, N. K. Hayward, J. P. Hugot, G. Jobin, D. Laukens, I. Lawrance, M. Lemann, A. Levine, C. Libioulle, E. Louis, D. P. McGovern, M. Milla, G. W. Montgomery, K. I. Morley, C. Mowat, A. Ng, W. Newman, R. A. Ophoff, L. Papi, O. Palmieri, L. Peyrin-Biroulet, J. Panes, A. Phillips, N. J. Prescott, D. D. Proctor, R. Roberts, R. Russell, P. Rutgeerts, J. Sanderson, M. Sans, P. Schumm, F. Seibold, Y. Sharma, L. A. Simms, M. Seielstad, A. H. Steinhart, S. R. Targan, L. H. van den Berg, M. Vatn, H. Verspaget, T. Walters, C.
Wijmenga, D. C. Wilson, H. J. Westra, R. J. Xavier, Z. Z. Zhao, C. Y. Ponsioen, V. Andersen, L. Torkvist, M. Gazouli, N. P. Anagnou, T. H. Karlsen, L. Kupcinskas, J. Sventoraityte, J. C. Mansfield, S. Kugathasan, M. S. Silverberg, J. Halfvarson, J. I. Rotter, C. G. Mathew, A. M. Griffiths, R. Gearry, T. Ahmad, S. R. Brant, M. Chamaillard, et al., 2011: Meta-analysis identifies 29 additional ulcerative colitis risk loci, increasing the number of confirmed associations to 47. Nat Genet, 43, 246-252.

Bartel, D. P., 2004: MicroRNAs: genomics, biogenesis, mechanism, and function. Cell,116, 281-297.

Caporali, A. and C. Emanueli, 2011: MicroRNA regulation in angiogenesis. Vascul Pharmacol, 55, 79-86.

Comer, B. S., B. Camoretti-Mercado, P. C. Kogut, A. J. Halayko, J. Solway and W. T. Gerthoffer, 2014: MicroRNA-146a and microRNA-146b expression and anti-inflammatory function in human airway smooth muscle. Am J Physiol Lung Cell Mol Physiol,307, L727-734.

Consortium, U. I. G., J. C. Barrett, J. C. Lee, C. W. Lees, N. J. Prescott, C. A. Anderson, A. Phillips, E. Wesley, K. Parnell, H. Zhang, H. Drummond, E. R. Nimmo, D. Massey, K. Blaszczyk, T. Elliott, L. Cotterill, H. Dallal, A. J. Lobo, C. Mowat, J. D. Sanderson, D. P. Jewell, W. G. Newman, C. Edwards, T. Ahmad, J. C. Mansfield, J. Satsangi, M. Parkes, C. G. Mathew, C. Wellcome Trust Case Control, P. Donnelly, L. Peltonen, J. M. Blackwell, E. Bramon, M. A. Brown, J. P. Casas, A. Corvin, N. Craddock, P. Deloukas, A. Duncanson, J. Jankowski, H. S. Markus, C. G. Mathew, M. I. McCarthy, C. N. Palmer, R. Plomin, A. Rautanen, S. J. Sawcer, N. Samani, R. C. Trembath, A. C. Viswanathan, N. Wood, C. C. Spencer, 
J. C. Barrett, C. Bellenguez, D. Davison, C. Freeman, A. Strange, P. Donnelly, C. Langford, S. E. Hunt, S. Edkins, R. Gwilliam, H. Blackburn, S. J. Bumpstead, S. Dronov, M. Gillman, E. Gray, N. Hammond, A. Jayakumar, O. T. McCann, J. Liddle, M. L. Perez, S. C. Potter, R. Ravindrarajah, M. Ricketts, M. Waller, P. Weston, S. Widaa, P. Whittaker, P. Deloukas, L. Peltonen, C. G. Mathew, J. M. Blackwell, M. A. Brown, A. Corvin, M. I. McCarthy, C. C. Spencer, A. P. Attwood, J. Stephens, J. Sambrook, W. H. Ouwehand, W. L. McArdle, S. M. Ring and D. P. Strachan, 2009: Genome-wide association study of ulcerative colitis identifies three new susceptibility loci, including the HNF4A region. Nat Genet,41, 13301334.

Coskun, M., J. T. Bjerrum, J. B. Seidelin, J. T. Troelsen, J. Olsen and O. H. Nielsen, 2013: miR-20b, miR-98, miR-125b-1*, and let-7e* as new potential diagnostic biomarkers in ulcerative colitis. World $J$ Gastroenterol, 19, 4289-4299.

Danese, S. and C. Fiocchi, 2011: Ulcerative colitis. N Engl J Med,365, 1713-1725.

Dennis, G., Jr., B. T. Sherman, D. A. Hosack, J. Yang, W. Gao, H. C. Lane and R. A. Lempicki, 2003: DAVID: Database for Annotation, Visualization, and Integrated Discovery. Genome biology, 4, P3.

Fabian, M. R., N. Sonenberg and W. Filipowicz, 2010: Regulation of mRNA translation and stability by microRNAs. Annu Rev Biochem, 79, 351-379.

Fasseu, M., X. Treton, C. Guichard, E. Pedruzzi, D. Cazals-Hatem, C. Richard, T. Aparicio, F. Daniel, J. C. Soule, R. Moreau, Y. Bouhnik, M. Laburthe, A. Groyer and E. Ogier-Denis, 2010: Identification of restricted subsets of mature microRNA abnormally expressed in inactive colonic mucosa of patients with inflammatory bowel disease. PLoS One, 5.

Finkel, T., M. Serrano and M. A. Blasco, 2007: The common biology of cancer and ageing. Nature,448, 767-774.

Griffith, O. L., A. Melck, S. J. Jones and S. M. Wiseman, 2006: Meta-analysis and meta-review of thyroid cancer gene expression profiling studies identifies important diagnostic biomarkers. Journal of clinical oncology : official journal of the American Society of Clinical Oncology, 24, 5043-5051.

Hubenthal, M., G. Hemmrich-Stanisak, F. Degenhardt, S. Szymczak, Z. Du, A. Elsharawy, A. Keller, S. Schreiber and A. Franke, 2015: Sparse Modeling Reveals miRNA Signatures for Diagnostics of Inflammatory Bowel Disease. PLoS One, 10, e0140155.

Kersten, S., 2010: Regulation of nutrient metabolism and inflammation. Results Probl Cell Differ, 52, 13-25.

Kurowska-Stolarska, M., S. Alivernini, L. E. Ballantine, D. L. Asquith, N. L. Millar, D. S. Gilchrist, J. Reilly, M. Ierna, A. R. Fraser, B. Stolarski, C. McSharry, A. J. Hueber, D. Baxter, J. Hunter, S. Gay, F. Y. Liew and I. B. McInnes, 2011: MicroRNA-155 as a proinflammatory regulator in clinical and experimental arthritis. Proc Natl Acad Sci U S A, 108, 11193-11198.

Lin, J., Q. Cao, J. Zhang, Y. Li, B. Shen, Z. Zhao, A. M. Chinnaiyan and M. P. Bronner, 2013: MicroRNA expression patterns in indeterminate inflammatory bowel disease. Mod Pathol,26, 148154.

Lin, J., N. C. Welker, Z. Zhao, Y. Li, J. Zhang, S. A. Reuss, X. Zhang, H. Lee, Y. Liu and M. P. Bronner, 2014: Novel specific microRNA biomarkers in idiopathic inflammatory bowel disease 
unrelated to disease activity. Mod Pathol,27, 602-608.

Medzhitov, R. and T. Horng, 2009: Transcriptional control of the inflammatory response. Nat Rev Immunol,9, 692-703.

Mosli, M. H., G. Zou, S. K. Garg, S. G. Feagan, J. K. MacDonald, N. Chande, W. J. Sandborn and B. G. Feagan, 2015: C-Reactive Protein, Fecal Calprotectin, and Stool Lactoferrin for Detection of Endoscopic Activity in Symptomatic Inflammatory Bowel Disease Patients: A Systematic Review and Meta-Analysis. Am $J$ Gastroenterol,110, 802-819; quiz 820.

Olaru, A. V., F. M. Selaru, Y. Mori, C. Vazquez, S. David, B. Paun, Y. Cheng, Z. Jin, J. Yang, R. Agarwal, J. M. Abraham, T. Dassopoulos, M. Harris, T. M. Bayless, J. Kwon, N. Harpaz, F. Livak and S. J. Meltzer, 2011: Dynamic changes in the expression of MicroRNA-31 during inflammatory bowel disease-associated neoplastic transformation. Inflamm Bowel Dis, 17, 221-231.

Olaru, A. V., S. Yamanaka, C. Vazquez, Y. Mori, Y. Cheng, J. M. Abraham, T. M. Bayless, N. Harpaz, F. M. Selaru and S. J. Meltzer, 2013: MicroRNA-224 negatively regulates p21 expression during late neoplastic progression in inflammatory bowel disease. Inflamm Bowel Dis, 19, 471-480.

Pooley, N., L. Ghosh and P. Sharon, 1995: Up-regulation of E-selectin and intercellular adhesion molecule-1 differs between Crohn's disease and ulcerative colitis. Dig Dis Sci,40, 219225.

Rouas, R., H. Fayyad-Kazan, N. El Zein, P. Lewalle, F. Rothe, A. Simion, H. Akl, M. Mourtada, M. El Rifai, A. Burny, P. Romero, P. Martiat and B. Badran, 2009: Human natural Treg microRNA signature: role of microRNA-31 and microRNA-21 in FOXP3 expression. Eur J Immunol,39, 1608-1618.

Scaldaferri, F., S. Vetrano, M. Sans, V. Arena, G. Straface, E. Stigliano, A. Repici, A. Sturm, A. Malesci, J. Panes, S. Yla-Herttuala, C. Fiocchi and S. Danese, 2009: VEGF-A links angiogenesis and inflammation in inflammatory bowel disease pathogenesis. Gastroenterology,136, 585-595 e585.

Schaefer, J. S., T. Attumi, A. R. Opekun, B. Abraham, J. Hou, H. Shelby, D. Y. Graham, C. Streckfus and J. R. Klein, 2015: $\quad$ MicroRNA signatures differentiate Crohn's disease from ulcerative colitis. BMC Immunol, 16, 5 .

Stewart, L. A., M. Clarke, M. Rovers, R. D. Riley, M. Simmonds, G. Stewart, J. F. Tierney and P.-I. D. Group, 2015: Preferred Reporting Items for Systematic Review and Meta-Analyses of individual participant data: the PRISMA-IPD Statement. JAMA,313, 1657-1665.

Suarez, Y., C. Wang, T. D. Manes and J. S. Pober, 2010: Cutting edge: TNFinduced microRNAs regulate TNFinduced expression of E-selectin and intercellular adhesion molecule-1 on human endothelial cells: feedback control of inflammation. $J$ Immunol, 184, 21-25.

Sun, Y., Q. Li, H. Gui, D. P. Xu, Y. L. Yang, D. F. Su and X. Liu, 2013: MicroRNA-124 mediates the cholinergic anti-inflammatory action through inhibiting the production of pro-inflammatory cytokines. Cell Res, 23, 1270-1283.

Taganov, K. D., M. P. Boldin, K. J. Chang and D. Baltimore, 2006: NF-kappaBdependent induction of microRNA miR-146, an inhibitor targeted to signaling proteins of innate immune 
responses. Proc Natl Acad Sci $U S$ A, 103, 12481-12486.

Takagi, T., Y. Naito, K. Mizushima, I. Hirata, N. Yagi, N. Tomatsuri, T. Ando, Y. Oyamada, Y. Isozaki, H. Hongo, K. Uchiyama, O. Handa, S. Kokura, H. Ichikawa and T. Yoshikawa, 2010: Increased expression of microRNA in the inflamed colonic mucosa of patients with active ulcerative colitis. $J$ Gastroenterol Hepatol,25 Suppl 1, S129-133.

Van der Goten, J., W. Vanhove, K. Lemaire, L. Van Lommel, K. Machiels, W. J. Wollants, V. De Preter, G. De Hertogh, M. Ferrante, G. Van Assche, P. Rutgeerts, F. Schuit, S. Vermeire and I. Arijs, 2014: Integrated miRNA and mRNA expression profiling in inflamed colon of patients with ulcerative colitis. PLoS One,9, e116117.

Wu, F., M. Zikusoka, A. Trindade, T. Dassopoulos, M. L. Harris, T. M. Bayless, S. R. Brant, S. Chakravarti and J. H. Kwon, 2008: MicroRNAs are differentially expressed in ulcerative colitis and alter expression of macrophage inflammatory peptide-2 alpha. Gastroenterology,135, 16241635 e 1624.

$\mathrm{Xu}$, N., F. Meisgen, L. M. Butler, G. Han, X. J. Wang, C. Soderberg-Naucler, M. Stahle, A. Pivarcsi and E. Sonkoly, 2013: MicroRNA-31 is overexpressed in psoriasis and modulates inflammatory cytokine and chemokine production in keratinocytes via targeting serine/threonine kinase 40. $J$ Immunol, 190, 678-688.

\section{How to cite this article:}

Yifei Cao, Chengtan Li, Wen Li, Yani Chen, WeibinCai, XiaohuaTan, Liangwen Xu, Lei Yang and Yutao Yan. 2016. Over expressed miRNA-31 is the Most Consistent and Unique Micro RNA in Ulcerative Colitis. Int.J.Curr.Res.Aca.Rev. 4(2): 147-159.

doi: http://dx.doi.org/10.20546/ijcrar.2016.402.018 